NOV O 1990

0911

DOE/ER/ $60860--3$

DE9 1001671

\title{
The Atmospheric Chemistry of Po-218
}

\author{
Final Report
}

September 30, 1990

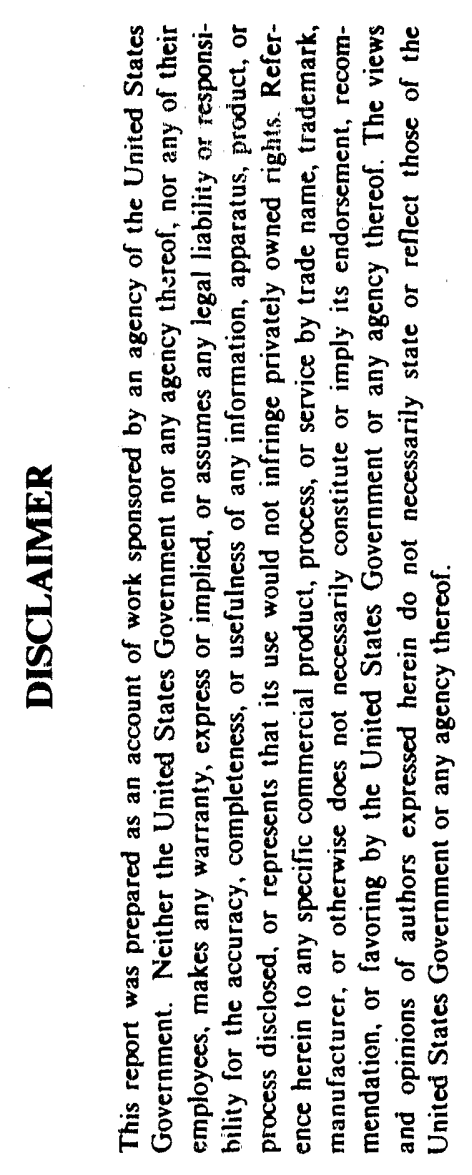

Contract No. DE FG02 89ER60860

Prepared for the

Office of Health and Environmental Research

U.S. Department of Energy

By

Philip K. Hopke

Department of Chemistry

Clarkson University

Potsdam, N.Y. 13699-5810 


\begin{abstract}
Atstract
The chemical and physical properties of ${ }^{218} \mathrm{Po}$ immediately following its formatic $n$ from ${ }^{222} \mathrm{Rn}$ decay are important in determining its behavior in indoor atmospheres and plays a major part in determining its potential health effects. In $88 \%$ of the decays, a singly charged, positive ion of ${ }^{218} \mathrm{Po}$ is obtained at the end of its recoil path. The neutralization rates for Po218 by the small ion recombination, electron transfer or electron scavenging mechanisms were previously reported. We have measured the small ion recombination rate in high purity gases to determine the negative small ion production rate as a function of the ionization potential of the gas. Our previous studies have also shown that radiolysis of water vapor by the recoiling Po ion produces high local concentrations of hydroxyl $(\cdot \mathrm{OH})$ radicals. These radicals can lead to oxidation of reactive trace gases and the neutral polonium molecule can become incorporated in ultrafine particles formed by the nucleation of low vapor pressure compounds produced by this radical oxidation process. The hydroxyl radical production rate and the production of particles are currently being studied.
\end{abstract}




\section{INTRODUCTION}

The health effects of the radon decay products are strongly dependent upon their behavior in the indoor atmosphere. Particularly for ${ }^{218} \mathrm{Po}$, the partitioning between the "unattached" state and the "attached" forms, combined with the preexisting aerosol particles, has a significant impact on the calculation of the dose to the lung resulting from a given decay product concentration. Thus, the chemical and physical behavior of the ${ }^{218} \mathrm{Po}$ atom immediately following its formation by the alpha decay of radon must be considered if its health implications are to be fully assessed.

\section{NEUTRALIZATION RATE MEASUREMENTS}

At the time when the alpha leaves the nucleus, there are two excess electrons around the residual polonium nucleus. It is probable that the exiting alpha causes autoionization leading to a positive ion. The recoiling polonium nucleus has a recoil energy of $117 \mathrm{keV}$ with a range in air of approximately 70 microns (Lind, 1961). The lon will be gas stripped to a moderate positive charge and then regain electrons as it slows toward thermal velocity such that at the end of the recoil path, $88 \%$ of the polonium atoms have $a+1$ charge and the remaining 12\% are neutral (Wellisch, 1913; Porstendorfer and Mercer, 1979). The study of the neutralization behavior of the polonium ion has been a major focus of the initial efforts of this project. The results of these studies have been reported by Chu and Hopke (1988). Their results can be applied to the understanding of the electrostatic collection of radon decay products particularly in radon measurement systems based on such collection. These studies have been described by Hopke (1989a). Thus, we now have a quantitative understanding of the neutralization behavior of ${ }^{218} \mathrm{Po}^{+}$in indoor air. To complete the basic studies of ${ }^{218} \mathrm{Po}^{+}$ neutralization, we have also measured the rate of neutralization by small ion recombination in a series of ultrapure gas atmospheres including oxygen, nitrogen, and argoil (Shi, 1989).

\section{RADIOLYTIC NUCLEI FORMATION}

As indicated previously (Ramamurthi and Hopke, 1989), the health effects of the radon decay products are strongly dependent upon the partitioning of the radon progeny between the "unattached" state and the "attached" forms. The differences in the diffusivity of these activity size modes has a significant impact on the calculated dose to the lung from a given decay product concentration. Previous studies had fucussed on the measurement of an 
operationally defiriud "unattached" fraction. Ramamurthi and Hopke (1989) have reviewed the prior use of wire screeris for the separation of the "unatiached" fraction. They found that the choice of a single, optimized screen $d_{p}(50 \%)$ parameter that maximizes the collection of the "unattached" mode while minimizing the collection of "attached" activity may be beneficial for single screen "unattached" fraction measurements. However, it is even better to measure the entire activity size distribution and then determine the activity fraction within the highly diffusive region of the size spectrum. The development of such a system is the focus of our other DOE/OHER project (Ramamurthi and Hopke, 1990). Our prior studies on radiolytic nuclei production have been summarized by Hopke (1989b). During the past year, we have pursued both experimental and theoretical studies of particle formation in our $2.4 \mathrm{~m}^{3}$ radonaerosol chamber (Karpen-Hayes and Hopke, 1990; Lao et al. 1990).

\section{OXIDATIVE RADICAL PRODUCTION}

A key factor in determining the role of radon radiolysis in indoor atmospheric chemistry is the concentration of. $\mathrm{OH}$ radical averaged over the entire air volume. Chu and Hopke (1988) estimated the. $\mathrm{OH}$ concentration in the immediate vicinity of the recoiling polonium atom but made no estimation for the average bulk concentration. Both the $\alpha$ and the recoil paths would contribute to this $\cdot \mathrm{OH}$ concentration. Studies are in progress to examine the $\cdot \mathrm{OH}$ concentration using the chemical multiplication chemiluminescence method of Cantrell et al. (1984). We have found a linear response of the chemiluminescent signal to changes in radon concentration in a mixture containing $10 \% \mathrm{CO}, 10 \mathrm{ppm} \mathrm{NO}, 20 \% \mathrm{O}_{2}, 40 \%$ relative humidity ( $\sim 10,000 \mathrm{ppm} \mathrm{H}_{2} \mathrm{O}$ ), and the remainder being $\mathrm{N}_{2}$ (Figure 1 ). We are working to calibrate this response in terms of the. $\mathrm{OH}$ concentration as well as measuring the response to variable $\mathrm{H}_{2} \mathrm{O}$ concentration at fixed radon levels. These studies will lead to an understanding of the rate of hydroxyl radical production that is occurring in indoor air as a result of radon radiolysis.

\section{SUMMARY}

The project has succeeded in achieving its initial objectives. We now have quantitative measurements of the rates of neutralization of ${ }^{218} \mathrm{Po}^{+}$for each of the various mechanisms that are available. These measurements have permitted the calculation of the effects of neutralization of the collection efficiency of the radon progeny, particularly in radon 


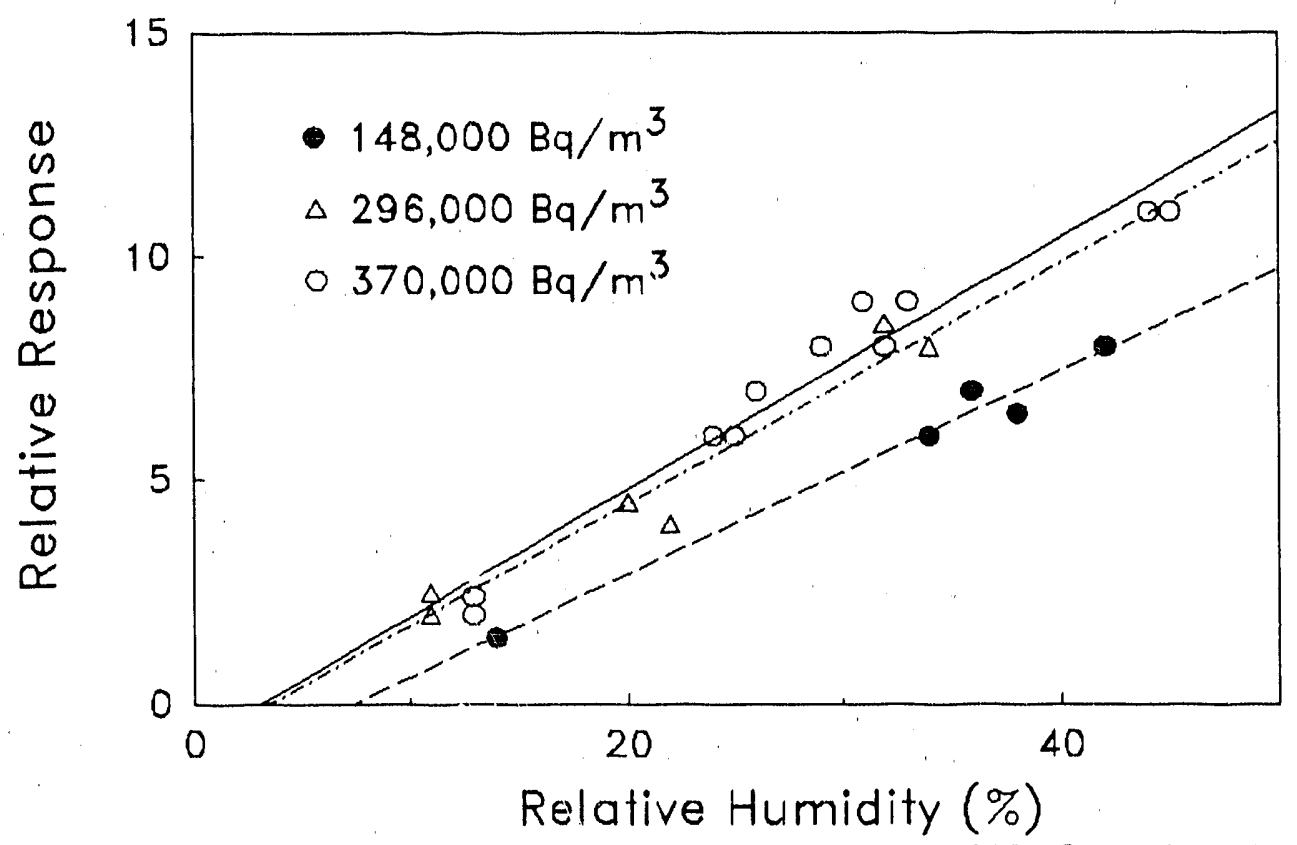

Figure 1. Relative Response of the Fluorescence Detector to the $\mathrm{NO}_{2}$ Chemiluminescence.

detectors that are based on the electrostatic collection of the decay products (Hopke, 1989a). We have improved our understanding of the formation of radiolytic nuclei and have shown that we can obtain a measurable response from the system design to determine the free radical production rates. We are now in a position to begin to obtain quantitative information of production rates of both free radicals and ion-induced nuclei. These studies will be continued under the new Department of Energy grant (DE FG02 90ER61029) that began July $1,1990$.

\section{PROJECT PERSONNEL}

Principal Investigator

Philip K. Hopke, Robert A Plane Professor of Chemistry

Assistant Research Scientist

Mukund Ramamurthi, July 1, 1990 to December 31, 1990.

Research Associate

Miaozhen Lao, December 1, 1990 to June $30,1990$. 
Graduate Research Assistants

Yefei Wu, Ph.D. Candidate in Chemistry, Clarkson University, September 1990 to June $30,1990$.

Wei Li, Ph.D. Candidate in Chemistry, Clarkson University, January 1990 to June 30, 1990.

Huiling Ding, Ph.D. Candidate in Chemistry, Clarkson University, February 1990 to June 30, 1990.

\section{PUBLICATIONS ARISING FROM THIS CONTRACT}

Hopke, P.K. (1989) Use of Electrostatic Collection of ${ }^{218}$ Po for Measuring Rn, P.K. Hopke, Hea'th Phys. 57:39-42.

Hopke, P.K., The Initial Behavior of ${ }^{218}$ Po in Indoor Air, Environment International 15:299-308 (1989),

Ramamurthi, M. and P.K. Hopke, Simulation Studies of Reconstruction Algorithms for the Determination of Optimum Operating Parameters and Resolution of Graded Screen Array Systems (Non-Conventional Diffusion Batteries), Aerosol Sci. Technol. 12:700-710 (1990).

Ramamurthi, M., R. Strydom and P.K. Hopke, Assessment of Wire and Tube Penetration Theories Using a ${ }^{218} \mathrm{PoO}_{x}$ Cluster Aerosol, J. Aerosol Sci. $21: 203-211$ (1990).

Winklmayr, W., M. Ramamurthi, R. Strydom, and P.K. Hopke, Size Distribution Measurements of Ultrafine Aerosols, $d_{p}>1.8 \mathrm{~nm}$, Formed by Radiolysis in a DMA Aerosol Neutralizer, Aerosol Sci. Technol. 13:394-398 (1990).

Hopke, P.K., The Initial Atmospheric Behavior of Radon Decay Products, in Indoor Air Pollution, J.G. Kay, Ed., Lewis Publishers, Chelsea, MI (in press, 1990).

M. Ramamurthi and P.K. Hopke, Addendum to "On improving the validity of wire screen unattached fraction Rn daughter measurements", Health Phys. 59:355-356 (1990).

\section{PRESENTATIONS OF RESULTS OF THIS CONTRACT}

The Measurement of Size Fras'ions of Radon Progeny, P.K. Hopke, presented at the Technical Measurements Center, operated by UNC Geotech for the Grand Junction Project Office, Grand Junction, Colorado, September 1989.

Formation of Ultrafine Aerosols $(0.5-20 \mathrm{~nm})$ from Radon Radiolysis. P.K. Hopke and $M$. Ramamurthi, R. Strydom, K.W. Tu, E.O. Knutson, R.F. Holub, W. Winklmayr, W. Marlow and 
S.C. Yoon, presented at the American Association for Aerosol Research, Reno, NV. October 1989.

Verification of Penetration Theories Using A Monodisperse Cluster Aerosol, $(D=0.078 \pm 0.003$ $\left.\mathrm{cm}^{2} / \mathrm{s}, \mathrm{d}_{\mathrm{p}} \approx 0.6 \mathrm{~nm}\right), \mathrm{M}$. Ramamurthi and P.K. Hopke, presented at the American Association for Aerosol Research, Reno, NV. October 1989.

DB-CNC Measurements of Radiolytic Ultrafine Aerosol Size Distributions, dp $>5 \mathrm{~nm}, \mathrm{M}$. Ramamurthi and P.K. Hopke, presented at the American Association for Aerosol Research, Reno, NV. October 1989.

Radon Decay Product Activity Size Distribution Measurement Methods - A Laboratory Intercomparision, M. Ramamurthi, P.K. Hopke, R. Strydom, K.W. Tu, E.O. Knutson, R.F. Holub, W. Winklmayr, W. Marlow and S.C. Yoon, presented at the American Association for Aerosol Research, Reno, NV. October 1989.

Potential for Forming Ultrafine Aerosols from Indoor Organic Vapors by Radon Decay Radiolysis-Induced Reactions, J.M. Daisey and P.K. Hopke, presented at AAAR 1990 Annual Meeting, PA., June, 1990.

Production of Sulfuric Acid Aerosol by Radiolytic Conversion of $\mathrm{SO}_{2}, \mathrm{~K}$. Karpen-Hayes and P.K. Hopke, presented at AAAR 1990 Annual Meeting, PA., June, 1990.

Measurement of the Effect of $\mathrm{SO}_{2}$ on the Polonium-218 Ion Mobility Spectrum by Alpha-Track Detection, S.C. Yoon, W.H. Marlow, P.K. Hopke, and M. Ramamurthi, presented at AAAR 1990 Annual Meeting, PA., June, 1990.

Modeling Radon Progeny Size Distribution in An Aerosol Chamber, M. Lao, K. Karpen-Hayes and P.K. Hopke, presented at the American Chemical Society Northeast Regional Meeting, June, 1990.

\section{REFERENCES}

Calntrell, C.A., Stedman, D.H., and Wendel, G.J. (1984) Measurement of atmospheric peroxy radicals by chemical amplification; Anal. Chem. 56:1496-1502.

Chis, K.D. and Hopke, P.K. (1988) Neutralization kinetics for Polonium-218, Environ. Sci. Technol. 22:711-717.

Hopike, P.K. (1989a) On the uss of electrostatic collection of radon decay products for measuring radon, Health Phys. 57:39-42.

Hop re, P.K. (1989b) The Initial Behavior of ${ }^{218} \mathrm{Po}$ in Indoor Air, Environment International 15:2:39-308.

Karpinn-Hayes, K. and P.K. Hopke (1990) Production of Sulfuric Acid Aerosol by Radiolytic Conversion of $\mathrm{SO}_{2}$, presented at AAAR 1990 Annual Meeting, PA., June, 1990. 
Lao, M., K. Karpen-Hayes and P.K. Hopke (1990) Modeling Radon Progeny Size Distribution in An Aerosol Chamber, presented at the American Chemical Society Northeast Regional Meeting, June, 1990.

Lind, S.C. (1961) Radiation Chemistry of Guses, Reinhold Publishing Corp., New York (1961). Linde Union Carbide (1985) Specialty Gases, 20:1:5,31,33.

Porstendörfer, J. and Mercer, T.T. (1979) Influence of electric charge and humidity upon the diffusion coefficient of radon decay products, Health Phys. 15, 191-199.

Ramamurthi, M. and Hopke, P.K. (1989) On improving the validity of wire screen unattached fraction radon daughter measurements. Health Phys. 56:189-194.

Ramamurthi M. and P.K. Hopke (1990) An Automated, Semi-Continuous System for Measuring Indoor Radon Progeny Activity-Weighted Size Distributions, $\mathrm{d}_{\mathrm{p}}$ : 0.5-500 nm, Aerosol Sci. Technol. (in press).

Shi, B. (1989) The Study of Neutralization of Po-218 Ions by Small Ion Recombination in $\mathrm{O}_{2} A r$, and $N_{2}$, Department of Energy Report DOE ER60546-4.

Wellisch, E.M. (1913) The distribution of the active deposition of radium in an electric field. II. Phil. Mag. 6(xxvi):623-635 (1913). 

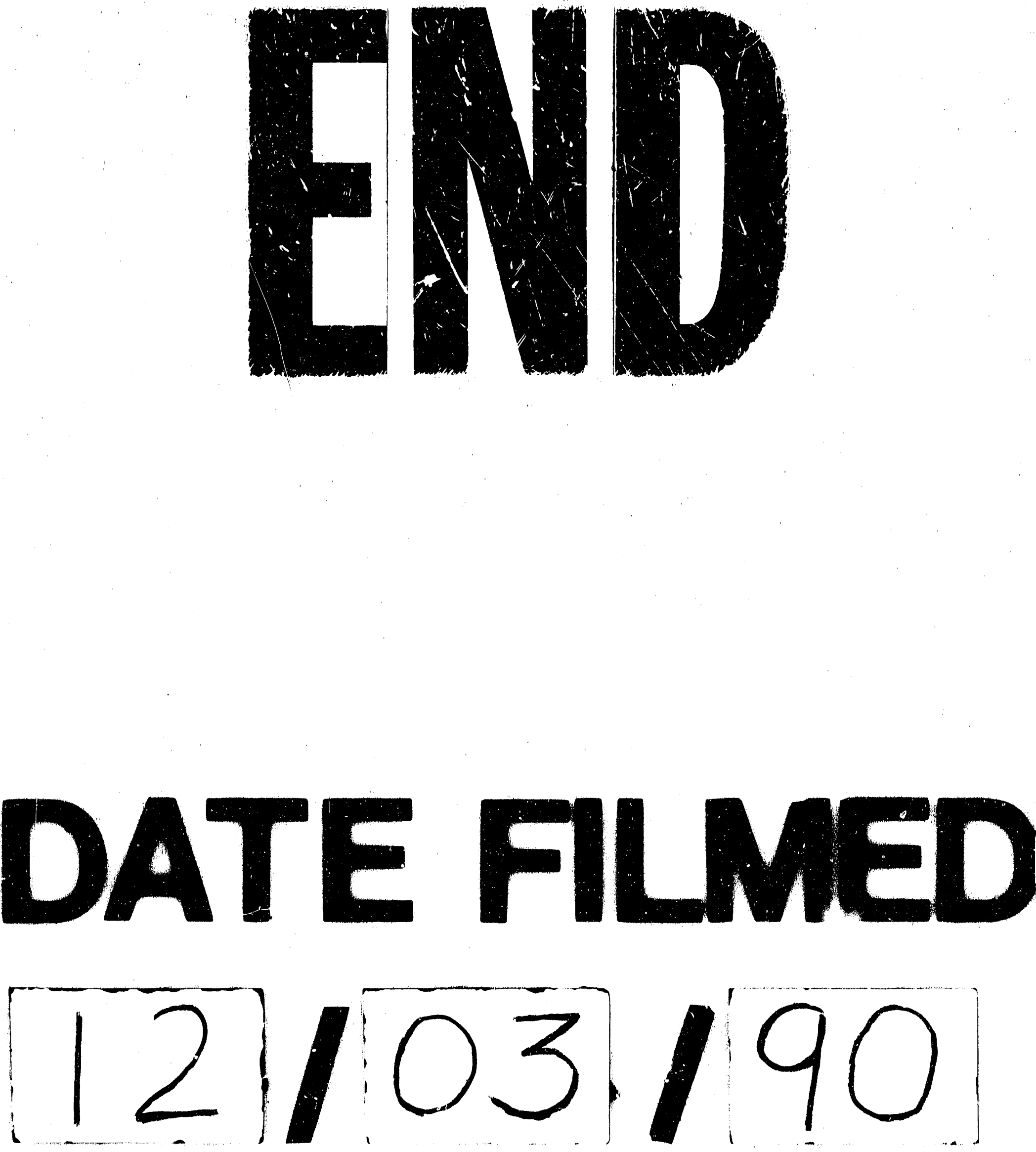
